\title{
Globalization and the Inward Flow of Immigrants: Issues Associated With the Inpatriation of Global Managers
}

\author{
Michael Harvey, Tim Kiessling, Miriam Moeller
}

\begin{abstract}
Assembling a diverse global workforce is becoming a critical dimension in gaining successful global performance. In the past, staffing has focused on control of the multinational organization as the primary goal when staffing overseas positions. As organizations globalize their operations, the goal of staffing is shifting from control to diversity, which in turn will provide the global organization with a means to gain/maintain competitive advantage. This diversity will be accomplished by integrating foreigners into the home country organization (i.e., inpatriation) through a permanent assignment. This article examines the inward flow of inpatriate managers by using social learning theory as a lens to better understand the means to integrate foreign managers into the domestic organization culture. The stages that inpatriate managers will go through (i.e., survival, integration, acculturation, and pluralistic integration) are explored to ascertain how to effectively utilize these global managers.
\end{abstract}

\section{Introduction}

Change is happening at an ever-increasing pace, and the current magnitude of change is unprecedented since the industrial revolution of the 1800s (Ocampo, 2002; Stiglitz, 2003; Thompson, 2002). Performance demands on global organizations have escalated at such an accelerating pace that hypercompetitive has become the standard for global competition, creating a complex competitive environment that necessitates organizational flexibility, innovativeness, improved communications, and management creativity (Debebe, 2008; Ghoshal \& Bartlett, 1997; Zadek, Hojensgard, \& Raynard 2001). The development of these dynamic capabilities requires strategic flexibility in the management of the global organization. 
Global organizations' success is increasingly a function of the resourcefulness and creativity of their managers, as well as of the flexibility of the human resource system for managing their worldwide human resources (Ghoshal \& Bartlett, 1997). The focus of this research is to assess the increase in diversity when inpatriating managers into the global organization and the resulting issues associated with increased diversity. Identifying, attracting, and retaining an adequate supply of inpatriate managers who have the necessary competencies to manage both cross-national and intra-national diversity is becoming one of the highest strategic priorities for global organizations (Harvey \& Novicevic, 2001; Reiche, 2006, 2007).

International human resource researchers have argued that the key to success in the global marketplace centers on putting together a diverse management team that has a holistic, pluralistic perspective on how to effectively facilitate global decision making (Courtney, 2001; Eisenhardt \& Zbaracki, 1992; Griffith, 2006; Harvey \& Novicevic, 2002; Keys \& Schwartz, 2007). At the present time it is becoming more difficult to assemble a team of managers who have the insight, experience, and willingness to take global organizations into the 21st century (Berry, 2006; Eden \& Miller, 2004; Hullermeier, 2005). Successful global organizations will learn how to attract, motivate and retain global managers (Harvey \& Novicevic, 2006; Harvey, Novicevic, \& Kiessling, 2001; Walsh, Shulman, \& Maurer, 2008).

Inpatriate managers (i.e., the selective transferring and/or hiring of local or third-country managers into the headquarters organization on a semipermanent to permanent basis for global leadership positions [Harvey, 1997]) can provide a unique frame of reference regarding the development of competitive strategy, given the inpatriates' tacit knowledge of their home country markets and culture. Inpatriate managers differ from expatriate managers in that the inpatriate manager is relocating to the home country of the organization. These managers can provide the codified knowledge as well as the tacit knowledge of doing business in emerging markets throughout the world. Inpatriate managers add valuable knowledge to global decision making. At the same time, inpatriate managers must be socialized into the culture of the headquarters organization for development of their management skills and eventually their global leadership capabilities (Harvey \& Buckley, 1997). Surveys of Fortune 100 companies suggest that United States-based organizations are increasingly using inpatriates in their operations (Solomon, 1995a; 1995b). In support of this claim, Scullion and Collings (2006) have empirically documented the growing practice of inpatriation among leading United Kingdom global organizations; those found in Germany have been documented as well (Reiche, 2006, 2007).

Global organizations that inpatriate foreign workers more effectively may experience increased organizational performance in the areas of increased profit, consumer satisfaction, and overall employee satisfaction. There will, 
however, be numerous other benefits that the global organization will experience due to the increased utilization of inpatriate managers. These benefits include: (1) a decrease in employee turnover, which directly corresponds to a decrease in recruitment costs; (2) the establishment of a "pipeline" to countries from which to recruit inpatriate managers; (3) increased productivity among all managers in the organization due to the strategic input of inpatriate managers; (4) the attraction of additional key inpatriate managers due to the past experience with recruiting select foreign managers; (5) the creation of a global competitive advantage; and (6) the reduction of the liability of foreignness perceived by key stakeholders in the global marketplace (Harvey, 1997; Harvey \& Novicevic, 2001, 2002; Harvey, Novicevic, \& Speier, 2002).

This paper addresses the issue of increasing the diversity of the management team of global organizations through inward immigration of inpatriate managers. The first section of the paper examines the value of viewing inpatriation and training of inpatriate managers through a social learning theory perspective. Second, the concept of inpatriation (i.e., inward immigrants to the headquarters organization) is introduced as a growing trend for staffing key global positions. And third, a section is included that examines how to integrate these inward immigrants effectively into the headquarters organization on a permanent basis and how to help ensure the development of a successful pluralistic management philosophy in the global organization.

\section{Learning to Adapt to the Social/Cultural Context of the Headquarters Organization: Social Learning Theory}

In an attempt to better understand the social/cultural learning that inpatriate managers must undertake to be accepted in the headquarters organization, one could use social learning theory (SLT). This theory is a behavioral theory of how one's behavior is developed. SLT differs from other behavioral theories, most notably from theories that view behavior as a function of the person (e.g., Adams, 1965; Locke, 1968; Vroom, 1964) or those that predict behavior as a function of the environment (Elkjaer, 2003; Luthans \& Ottemann, 1973; Miller, 1978; Porter \& Lawler, 1968). SLT combines the two theories and predicts behavior based on the interaction of the person (e.g., internal construct) and the environment (e.g., the external construct).

What is critical is to examine the potential difficulties inpatriate managers experience in adapting to the headquarters' home country's cultural standards both at the organizational as well as the macro cultural levels. The cultural distance between the inpatriate managers' home country and that of the headquarters organization can be used as a quasi indicator of the level of cultural displacement and culture shock that the inpatriate manager (and family) will experience upon relocation to the headquarters' home country (Eden \& Miller, 2004). The potential "disconnect" between the inpatriate manager and 
the environment is a critical issue when developing training programs for inpatriate managers who have different levels of cultural distance/novelty when entering the home country of the headquarters organization (Ward \& Masgoret, 2006).

SLT proposes that direct experiences with learning and level/rate of adjustment in the new organizational/macro-environment leads to the acquisition of specific beliefs about the consequences of behaviors and circumstances. These beliefs shape an individual's behavior (Bandura, 1976; Mischel, 2007). The interaction or reciprocal determinism of the SLT provides for the following predictions:

1. Environment to beliefs: Events in a inpatriate manager's environment directly influence beliefs about the consequences of behavior.

2. Beliefs to behavior: Beliefs about consequences influence/modify an inpatriate manager's behavior.

3. Behavior to environment: The behavior shapes an inpatriate manager's environment.

4. Behavior to belief: When the inpatriate manager performs a behavior and observes its consequences, these observations either reinforce or challenge beliefs held by the inpatriate manager based upon his/her own home country environment (Bandura, 1976, 1977).

While the SLT model seems rather obvious today, both internal and external constructs should be considered when analyzing behavior in complex environmental settings. The importance of SLT in understanding and/or predicting inpatriate manager's behavior is critical. The rationale behind SLT is that learning from the home country managers as well as training programs would accelerate the rate and quality of learning of the inpatriate manager (Elkjaer, 2003; Mischel, 2007). Given the potential cultural/social distance between the inpatriate's home environment and that of the headquarters organization, the SLT model can be pivotal in understanding the resulting adjustment and behavior of the inpatriate manager.

\section{The Development of Inpatriation Programs for the Inward Immigration of Foreign Managers}

Inpatriation programs will "provide individuals with useful information for reducing uncertainty associated with the impending international transfer and for forming accurate expectations about living and working in the prospective host country" (Black, Mendenhall, \& Oddou, 1991, p. 306). This goal will be accomplished through predeparture training and postarrival training/integration. There are a number of factors that organizations must keep in mind when 
developing a strong inpatriation program (Esses, Wagner, Wolf, Preiser, \& Wilbur, 2006; Harvey \& Novicevic, 2002; Harvey, Novicevic, \& Speier, 2002; Reiche, 2007).

To develop a training program for inpatriate employees, the goals of the training program, the trainer and his/her preparations, the training materials, and the composition of the training group as a confounding component relative to the inpatriate manager need to be addressed. In that light, a basic set of goals for inpatriate managers' training would include the following:

1. Increase participants' awareness of environment (internal/external) differences between the home country/organization and that of the headquarters, and illustrate how these differences will affect business operations.

2. Provide in-depth understanding of the "language" of business to ensure consistent business concept foundations among all inpatriate managers.

3. Increase participants' awareness of culturally/socially-based issues, indicating that not all concepts are universally shared by inpatriates.

4. Provide multidimensional skills training in functional business areas, interpersonal communication, and language, as well as skills training in adjustment, adaptation, and stress management.

5. Provide the inpatriate with an understanding of the inpatriate manager's career path and the importance of successful accomplishment of the inpatriate manager program to the long-run success of the company.

6. Provide the inpatriate manager with a skills profile evaluation before and after the training program that highlights his or her strengths and weaknesses (Harvey, Ralston, \& Napier, 2000).

An additional goal of the inpatriate training program would be to assist family members with their adjustments to the relocation to the home country of the organization. For more additional assessment of the process of inpatriation and inpatriate training programs, see Harvey (1997); Harvey, Novicevic, \& Speier (2002); and Reiche (2007).

The outline of this inpatriation program incorporates all of the factors associated with an organization's assessment of its organizational culture, task environment, and people (as described above). Thus, the goal of the inpatriation program is to decrease the degree of uncertainty associated with the change that foreign managers face when entering a domestic organization. By decreasing this uncertainty, there is a greater chance that adjustment into the organization and culture will be accomplished (Ward \& Masgoret, 2006, 2008). Adjustment into the organization and culture enables the inpatriate manager to deliver services more effectively and efficiently, which in turn makes the others in the organization more satisfied, thus decreasing the perception of liability of foreignness of the inpatriate manager (Eden \& Miller, 2004; Matsuo, 2000; Mezias, 2002; Sethi \& Guisinger, 2002). 


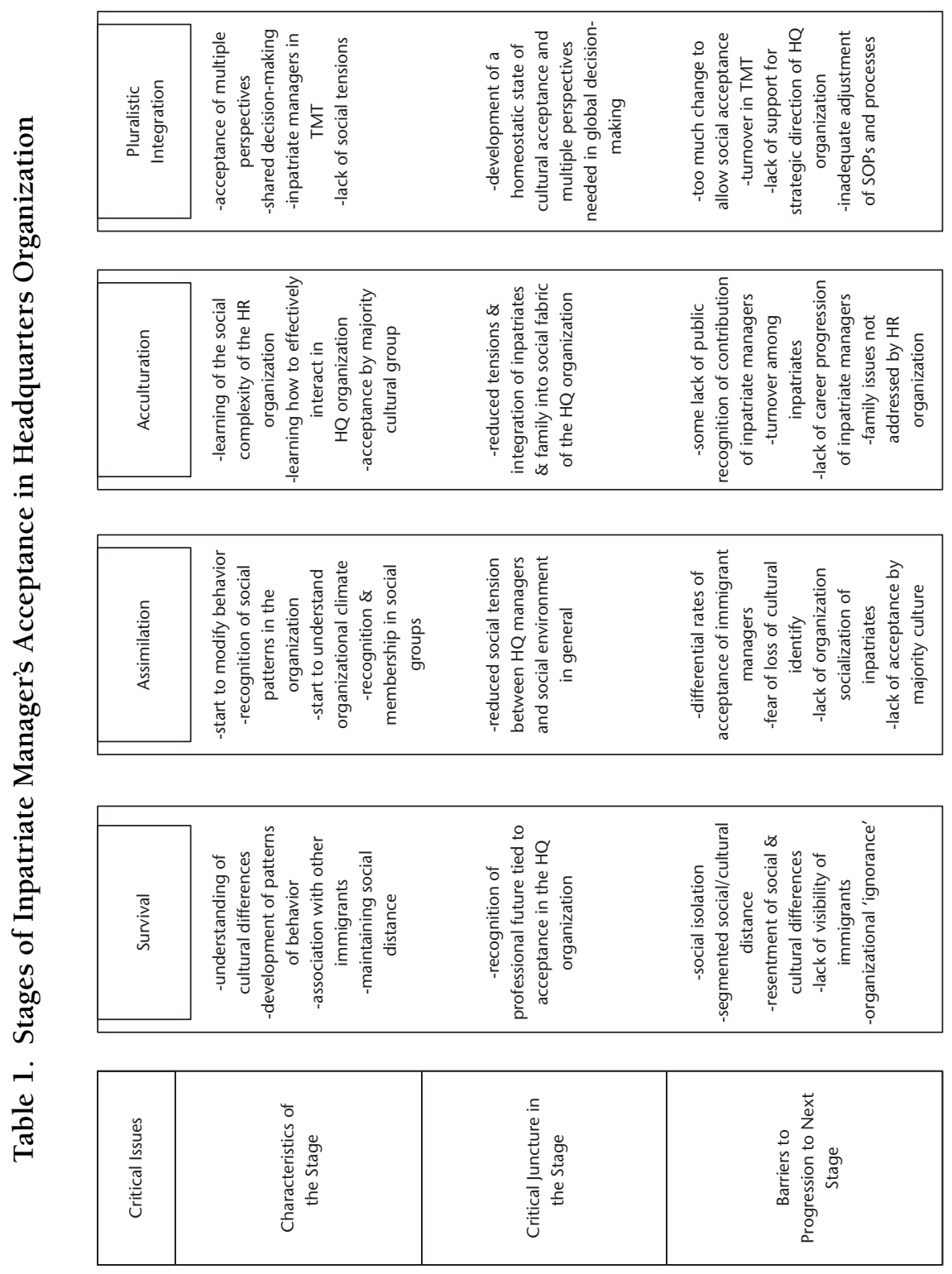




\section{Developing the Framework for Continuous "Reintegration" of Inpatriate Managers into the Headquarters Organization}

Integration into an organization can take on a number of different levels. Table 1 highlights four levels of organizational integration to which a organization can aspire, with the payoff being increased organizational performance (as measured by increased profit, consumer satisfaction, and overall employee satisfaction) after each level of organizational integration and, ultimately, the reduction of the liability of foreignness. The four levels of organizational integration are (1) survival, (2) assimilation, (3) acculturation, and (4) pluralistic integration.

Before discussing how the organizational integration process of inpatriate managers can be implemented, we will briefly define and discuss each level of organizational integration. Each stage can be compared with different stages of needs/motivation of the inpatriate manager (Vroom, 1964). The different levels of needs (and their comparative level of organizational integration) are physiological and safety needs (survival level of organizational integration), belonging needs (assimilation level of organizational integration), esteem needs (acculturation level of organizational integration), and self-actualization needs (pluralistic level of organizational integration). The higher-order needs (belonging, esteem, and self-actualization) are of no importance until the lowerorder needs (i.e., physiological and safety) are completely or partially satisfied. Once a need is completely or partially satisfied, an individual will seek to satisfy the need at the next higher level to build his or her cross-cultural competencies (Debebe, 2008). In an effort to provide future direction to inpatriate researchers, eight research propositions are presented relative to the four stages of integration of inpatriate managers to the home country organization.

I. Survival. The characteristics of the first stage of organizational integration (e.g., physiological/safety needs) of inpatriate managers are to find safety in the workplace activities, stability in the work environment, and security in performing job tasks around work colleagues. At this stage, structure, order, and limitations are set in place for the inpatriate manager, whereby they can then work to overcome the fears and anxieties of working in the home country of the headquarters. Inpatriate immigrants will, therefore, begin to positively contribute more to the management team once mere survival is achieved in the work environment (e.g., SLT). As policies and procedures are learned, inpatriate managers will become more comfortable in the context of both the organization and the macro-environment.

The stage of survival is critical for inpatriate managers to operationalize their routine behaviors in the work context (Elkjaer, 2003). At the same time, adaptation to the environment outside the organization can better be dealt with by the inpatriate manager. At this stage, the learning curve of the inpatriate manager should be improving dramatically as he or she attempts to digest information from 
the organizational culture, the task environment, his or her counterparts and the nonwork environment. In fact, during this stage, inpatriate managers may have to sublimate their traditional cultural beliefs in order to survive (Montuori \& Fahim, 2004). The faster the inpatriate worker can move through the survival stage, the quicker he or she will satisfy physiological and safety needs, allowing the inpatriate to move on to the next stage of organizational integration. From an organizational perspective, the faster the inpatriate worker can move through the survival stage, the faster the organization will begin to reap the payoff of increased organizational performance (Dirks, 1999; Elkjaer, 2003). Understanding that inpatriate managers go through this stage of organizational integration will further emphasize the importance of the inpatriation program that organizations implement. Each step taken toward pluralism hereafter requires increased levels of comfort in the new culture and environment by the inpatriate managers (Ward \& Masgoret, 2006).

After each stage, the process of "reintegrating" the inpatriate worker results in a change in perspective, from interpreting the uncertainty of their new lifestyle as a drastic "change" to interpreting it as a mere "contrast" of lifestyle (Montuoir \& Fahim, 2004). This process works at each level of organizational integration (i.e., survival to assimilation, assimilation to acculturation, acculturation to pluralism) and continues until the inpatriate worker reaches pluralism. It is more beneficial for inpatriate workers, as well as for the organizations, to move through these stages of organizational integration faster, as increased organizational performance and the reduction of the liability of foreignness would result more quickly. However, each stage of reintegration becomes increasingly difficult as the inpatriate worker moves towards pluralism. As previously mentioned, after each stage of organizational integration is completed, the organization will experience increased organizational performance in any or all of the areas by ways of increased profit, increased consumer satisfaction, and/or increased employee satisfaction (Dirks, 1999). These areas of increased organizational performance will be the measurement that confirms the reduction of the liability of foreignness perceived by key employees/managers (i.e., those who interact with or are supervised by the inpatriate manager). This leads to the following research propositions:

RESEARCH PROPOSITION 1: To assist in providing the infrastructure for immigrant managers to survive entry into the headquarters organization, personal safety and security mechanisms/process must be implemented.

ReSEARCH PROPOSITION 2: Headquarters' personnel need to be made aware of the potential instability and hostility of the organization environment for immigrant employees.

II. Assimilation. Once survival is achieved, the inpatriate worker proceeds into "assimilation" stage. Characteristics of this stage of organizational integration are the development of relationships and the recognition of a sense of 
community. Inpatriate managers will find themselves working to assimilate into the organization by recognizing that they are part of a group or team (e.g., not simply a foreign employee, but a key manager in the organization), so as to overcome social anxieties or lack of camaraderie within the organization (Lowell, Findlay, \& Stewart, 2004; Walsh, Shulman, \& Maurer, 2008). The host organizations will begin to see the benefits of increased profit, inpatriate satisfaction, and/or employee satisfaction when the inpatriate manager quickly, actively, and confidently assimilates into the organization.

Mentoring (i.e., the personal relationship in which a more experienced [usually older] group/organizational member acts as a guide, teacher, role model, or sponsor of a less experienced [usually younger] inpatriate member of the organization) has been viewed as a means for improving individual learning and career development (Burke \& McKeen, 1997; Chandler \& Kram, 2005). It is also considered instrumental in the initiation and maintenance of employee socialization in organizations (Clark, Harden, \& Johnson, 2000; Heimann \& Pittenger, 1996; Johnson, 2002; Payne \& Huff, 2005). To that end, a multitude of companies in a myriad of industries have established both formal and informal programs designed to help relocated inpatriate managers "learn the ropes."

During assimilation, minority groups gradually begin to adopt the customs and attitudes of the prevailing macro organization cultures (Alba \& Nee, 1997; Ward \& Masgoret, 2006). Thus, the survival skills that the inpatriate worker learned during the initial stage of organizational integration form a foundation of trust with domestic managers (Childs \& McMackin, 1996; Kramer \& Tyler, 1996; Cox, 2004). Using the similar-attraction paradigm to explain this assimilation process, it can be concluded that when inpatriate managers adapt to their new culture, they create links of similarity with current employees and consumers, which consequently creates attraction with one another (Zhou, 1997; Harvey, Ralston, \& Napier, 2000). Assimilation helps the inpatriate manager attain a feeling of belonging, which, in essence, is having some degree of social acceptance and approval from the culture, organization, and people with whom he or she interacts. This leads to the following research propositions:

Research Proposition 3: Inclusion into functional and social groups needs to be facilitated by headquarters personnel without relegating immigrants to "foreign" social groups that support cultural differences (e.g., the Spanish inpatriate social club); rather, include the immigrant in core organizational groups both functional and social.

Research Proposition 4: Assessment of relocated inpatriate managers/immigrants' satisfaction should be conducted on a regularly scheduled time interval to monitor changes in attitudes toward inclusion in the headquarter organization. 
III. Acculturation. Following assimilation, the inpatriate manager will start to become "acculturated" to the organizational climate and culture. Characteristics of this stage of organizational integration are the development of respect from other managers (Walsh, Shulman, \& Maurer, 2008), the quest for continual improvement and self-improvement within the organization, the feeling of increased confidence and competence towards job activities and interaction with people, and the formation of a reputation within the organization and toward people utilizing the organization.

Achieving the acculturation level of organizational integration will result in the process whereby a minority group's culture and a majority group's culture are gradually modified as a result of interaction with one another (Rohmjann, Florack, \& Piontkowski, 2006). After assimilation, when a foundation of trust has been established, the similar-attraction paradigm starts working in the opposite direction, resulting in current employees beginning to inquire into the culture of inpatriate managers. This situation arises because the inpatriate worker is continually increasing his or her self-confidence and self-efficacy as a result of the respect shown by the culture, organization, and people with whom they interact (Leonard, Beauvais, \& Scholl, 1999; Mruk, 2001).

The strengthening of the relationship between these two groups of managers provides an environment where uncertainty between the two cultures continues to decrease and the modification of cultures progresses. This "lessuncertain" environment bonded by trust creates stronger employee relationships, a better environment for the delivery of services, and ultimately increased profits for the organization (Montuori \& Fahim, 2004). This leads to the following research propositions:

Research PROPOSITION 5: Recognition and/or rewards for the specific inputs on global projects of immigrant workers by headquarters management need to be institutionalized in the organization.

Research PROPOSITION 6: Efforts should be made to increase the visibility of immigrant managers and to promote their contribution to the global successes of the organization.

IV. Pluralistic Integration. After "reintegrating" one final time, the inpatriate manager reaches the stage of "pluralism." The characteristics of the pluralistic stage of organizational integration are the development of a set of democratic values, social interest, compassion, and humanity. Additionally, creativity is established, intimate personal relationships are fostered, acceptance of self and others becomes fulfilled, and diversity of thought and presence is encouraged. This level of organizational integration is inordinately difficult to attain.

Pluralism is the condition whereby numerous distinct ethnic, religious, or cultural groups are present and tolerated within a society (Harvey \& Novicevic, 
2001). There is never an end point to this stage of organizational integration. Pluralism denotes the recognition and acceptance of alternative views of thought, opinion, and action (i.e., the performing of business operations) in an organization's culture. It is at this stage of organizational integration that a competitive advantage for the organization is created, because there are no stipulated, centric ways of handling situations, which fosters the environment for the development and implementation of business operations promoted from alternative views of thought, opinion, and action. Diversity thrives during pluralism, because, as mentioned previously, the resulting team of managers in the pluralistic organization creates competition amongst themselves (i.e., positive conflict), thus forcing alternative ways to solve problems, pride in work outcomes, and, ultimately, increased success in operations (Harvey $\&$ Novicevic). Furthermore, this process is very difficult to duplicate by competitors. This competitive advantage ultimately increases the organization's performance from the perspective of increased profit and increased satisfaction from consumers and employees.

How can pluralism be applied to headquarters organizations? Pluralism raises four questions specific to a global organization's operations:

1. Are the stipulated policies and procedures of the organization producing the desired behaviors?

2. Are the stakeholders (e.g., employees) within the organization being held back and/or limited in their behavior by the policies of the global organization?

3. Are management controls artificially placing boundaries on where the organization's strategy is going?

4. Is the organization consistently reinventing itself to the point that its culture is never "settled" and/or internalized by global managers? (Harvey \& Novicevic, 2001)

The multicultural work environment created from the inpatriation of foreign managers will draw on these four questions to ultimately improve the headquarters organization. As an example, managers will begin to ask whether they are treating a person's "condition" or "disease," rather than treating the "person." In other words, managers will deliver services based on healing the person. By approaching delivery in this fashion, managers will have the autonomy to treat consumers wholly, uniquely, and in a manner designed to meet their level of satisfaction. In doing so, the foundation of trust developed during the assimilation stage will have been bridged, first from the inpatriate worker to current employees within the organization, and second from the inpatriate worker to the consumer. The consumers, because of the positive way in which they are treated, will experience a high level of satisfaction with the organization, which will lead them (not to mention new consumers, because of the positive word-of-mouth advertising) back to the organization the next 
time they require services. As a result, all three indicators of organizational performance will increase.

Additionally, pluralism will have limited the liability of foreignness perceived by others in the organization. As inpatriate managers are assessed in an organization, they will not only witness the pluralistic freedom of treatment and operations, but the pluralistic nature and interaction between managers (e.g., Indian and Jamaican inpatriates working in conjunction with American and Canadian managers). The trust among any combination of managers is subsequently passed along to the organization's culture, which in turn validates this trust. The result is the limitation of the perception of the liability of foreignness, leading to the following propositions:

ReSEARCH PROPOSITION 7: Shared decision making and support for divergent views of issues facing the organization should be implemented in the organization.

ReseARCH PROPOSITION 8: Support for multiperspective cultural standards and value of cultural inputs is needed to successfully include immigrants in the headquarters organization.

\section{The Potential Positive Impact of Inpatriate Managers}

It is important for the headquarters organization to understand that inpatriates will not all require the same inpatriation program or experience the same challenges when integrating into an organization (Reiche, 2007). It is for this reason that the first two sections of this paper were included, as they determine the starting point not only by which organizations could begin to target foreign managers but also from which to develop a personalized inpatriation program. Using country-of-origin designation of inpatriated managers not only will allow headquarters organizations to target countries with an ample supply of potential inpatriate managers but also will encourage management at the headquarters organization to analyze the environment from which inpatriates are immigrating and to develop unique programs on the relative social/cultural/economic category of countries (see Table 2).

Measuring culture distance not only allows a headquarters organization to target countries that are more similar to the headquarters, but it also provides a rough starting point to begin the customized inpatriation program (Kosic \& Phalet, 2006). With the starting point of the inpatriation program established, organizations can begin to make decisions about how to prepare inpatriate managers for integration into the organization. In general, organizations will expect foreign managers coming from countries with wellrespected systems and low culture distance to integrate rather quickly through the survival and perhaps even assimilation stages of organizational integration. However, managers coming from countries with less-esteemed systems and 
Table 2. Socialization of Inpatriate Managers to Headquarters Organization

\begin{tabular}{|c|c|c|c|c|c|}
\hline $\begin{array}{l}\text { Level in } \\
\text { Organization/Sex }\end{array}$ & $\begin{array}{l}\text { Category1* } \\
\text { Cultural/Eco. }\end{array}$ & $\begin{array}{c}\text { Category } 2 \\
\text { Cultural/Eco. }\end{array}$ & $\begin{array}{c}\text { Category } 3 \\
\text { Cultural/Eco. }\end{array}$ & $\begin{array}{c}\text { Category } 4 \\
\text { Cultural/Eco. }\end{array}$ & $\begin{array}{c}\text { Category } 5 \\
\text { Cultural/Eco. }\end{array}$ \\
\hline \multicolumn{6}{|l|}{$\begin{array}{l}\text { Top Mgt. } \\
\text { Male }\end{array}$} \\
\hline \multicolumn{6}{|l|}{ Female } \\
\hline \multicolumn{6}{|l|}{$\begin{array}{l}\text { Middle Mgt. } \\
\text { Male }\end{array}$} \\
\hline \multicolumn{6}{|l|}{ Female } \\
\hline \multicolumn{6}{|l|}{$\begin{array}{r}\text { Supervisory Mgt. } \\
\text { Male }\end{array}$} \\
\hline Female & & & & & \\
\hline
\end{tabular}

high culture distance will not achieve organizational integrating as quickly. It can be seen that the "rigor" associated with these two inpatriation programs will be vastly different based on this initial analysis.

The headquarters organization can then take this starting position for the inpatriation program and expand its depth by developing "integration criteria" based on the three aspects by which the inpatriation process was developed: the organizational culture, the task environment, and the people. It is also important to address non-work factors. Headquarter organizations can rank foreign managers during the selection process based on certified questions to measure specific qualities depending on the method used to rate candidates (e.g., Prospector method, Big Five Personality Characteristics, etc.). As the selection process proceeds, the organization can rate the candidates using a scale (e.g., Likert scale) which is based on validated questions to measure specific qualities (e.g., sensitivity to cultural differences, learning style, ability to handle conflict, etc.). The outcome of this measurement technique can be a powerful method by which to identify and assist the inpatriate worker in navigating the areas that would cause the greatest uncertainty when entering headquarters home market and the new organization.

Headquarters organizations that inpatriate foreign managers will experience increased organizational performance in the areas of increased profit, consumer satisfaction, and overall employee satisfaction. There will, however, be 
numerous other benefits that the headquarters organization will experience. These benefits include: (1) a decrease in employee turnover which directly corresponds to a decrease in recruitment costs; (2) the establishment of a "pipeline" to countries from which to recruit inpatriate managers; (3) increased productivity among all managers in the organization; (4) the attraction of additional inpatriate managers; (5) the creation of a competitive advantage; and (6) the reduction of the liability-of-foreignness perceived by those in the organization (Harvey, 1997; Harvey \& Novicevic, 2001, 2006; Harvey, Novicevic, \& Kiessling, 2001).

\section{Summary/Conclusion}

The global marketplace has formed new dynamics which are creating opportunities as well as competitive issues. Successful global performance will require management teams to be cross-national and heterogeneous to develop a pluralistic and holistic mind-set. One trend that major, successful firms seem to be following is the use of inpatriates to fulfill the new global managerial requirement. Yet not only is it difficult to attract, motivate, and retain the required global managers, the organization itself will have to establish procedures to facilitate their success.

Our research has explored many of the major reasons for globalization and the interrelatedness of relying on new staffing models for organizational success. Due to the required utilization of inpatriates from a social learning theory foundation perspective, inpatriation development programs will be pivotal in understanding the resulting adjustment and behavior of the inpatriate manager. The adjustment of a manager brought to the home country headquarters of a foreign national (inpatriation) allows the inpatriate to more quickly and effectively become a valued asset to the firm.

We have developed several models to assist organizations in ensuring the success of inpatriates through the four levels of integration: (1) survival; (2) assimilation; (3) acculturation; and (4) pluralistic integration. For survival, the inpatriate will have to become acculturated to his or her new environment, and the organization will need to facilitate this process by providing the infrastructure and support. Through the selection process of determining the inpatriate manager, the selected individual has been identified as having the characteristics to personally be successful, but the organization will have to train headquarters personnel to be aware of the potential "liability of foreignness" issues that could create instability and hostility.

The next level for success for inpatriate managers is that of assimilation, or the feeling of belonging and social acceptance and approval of the organization. The organization should discourage ethnocentric subgroups (e.g., social clubs for only those from particular countries), as these lead to stereotypes. Although introducing families to like-type communities to encourage acculturation on a personal level is helpful, the organization should not promote 
disparate subgroups within the working environment. To determine the success of both the inpatriate's efforts and the organization's, regularly scheduled sessions should be held to assess satisfaction towards their feelings of inclusion into the organization climate. These sessions not only assess the satisfaction of the individual, but also will provide feedback for continued adjustment to the inpatriation program.

Over time, through the efforts of both the firm and the individual, the inpatriate becomes acculturated and has developed strong relationships. As such, headquarters will need to institutionalize recognition for specific inputs on global projects by the inpatriate managers. The increase in visibility of inpatriates will assist in the development of respect from other managers and increase their confidence within the organization.

The final level and the major goal of the organization is to develop a pluralistic mind-set in which numerous distinct ethnic, religious, or cultural groups are present and tolerated. This diversity will cause conflict, which forces alternative ways in solving problems, pride in work outcomes, and success in outcomes. To deliver these superior results, the organization should implement mechanisms to support divergent views and shared decision making. These multicultural standards and support for the value of multicultural inputs will also further provide a basis for inpatriate success.

In summary, the benefit from the new staffing model of inpatriates will be increased organizational performance. However, this will not be an easy change, and our research illustrates the areas an organization must address to increase the success of these inpatriate managers in the home country organization. As each firm is different, each individual is different, each home country is different, and each host country is different, the tailoring of the socialization process for inpatriate managers to these levels and diverse components will be exacerbated. However, for the long-term success of the firm, it can be argued that the return is worth the effort.

\section{References}

Adams, J. S. (1965). Inequality in social exchange. In L. Berkowitz (Ed.), Advances in experimental social psychology (Vol. 2, pp. 267-299). New York: Academic Press.

Alba, R., \& Nee, V. (1997). Rethinking assimilation theory for a new year of immigration, International Migration Review, 31(4): 826-874.

Bandura, A. (1976). Social learning theory. In J. T. Spence, R. C. Carson, \& J. W. Thibaut (Eds.), Behavioral approaches to therapy (pp. 1-46). Morristown, NJ: General Learning Press.

Bandura, A. (1977). Self-efficacy: Towards a unifying theory of behavior change. Psychological Review, 84, 191-215.

Berry, J. (2006). Mutual attitudes among immigrants and 'ethnocultural' groups in Canada. International Journal of Intercultural Relations, 30, 719-734.

Black, M., \& Oddou, (1991). Toward a comprehensive model of adjustment: An integration of multiple theoretical perspectives, Academy of Management Review, 16(2), 291-317.

Burke, R. J., \& McKeen, C. A. (1997). Benefits of mentoring relationships among managerial and professional women: A cautionary tale. Journal of Vocational Behavior, 51, 43-57. 
Chandler, D. E., \& Kram, K. E. (2005). Mentoring and developmental networks in the new career context. In H. Gunz \& M. Peiper (Eds.), Handbook of career studies. Thousand Oaks, CA: Sage Publications.

Childs, T., \& McMackin, J. (1996). Integrating variable risk preferences, trust, and transaction cost economics. Academy of Management Review, 21(1), 73-99.

Clark, R. A., Harden, S. L., \& Johnson, W. B. (2000). Mentor relationships in clinical psychology doctoral training: Results of a national survey. Teaching of Psychology, 27, 262-268.

Courtney, J. (2001). Decision-making and knowledge management in inquiring organizations: Toward a new decision-making paradigm for DSS. Decision Support Systems, 31(1), 17-38.

Cox, J. (2004). How to identify trust and reciprocity, Games and Economic Behavior, 46, 260-281.

Debebe, G. (2008). Cross-cultural competence and power-based rules: A native American case study. International Journal of Intercultural Relations, 32, 399-414.

Dirks, K. (1999). The effects of interpersonal trust on work group performance. Journal of Applied Psychology, 84, 445-455.

Eden, L., \& Miller, S. (2004). Distance matters: Liability of foreignness, institutional distance and ownership strategy. In M. Hitt \& J. L. Cheng (Eds.), The evolving theory of the multinational firm: Advances in international management, Vol. 16. Amsterdam, The Netherlands: Elsevier.

Eisenhardt, K., \& Zbaracki, M. (1992). Strategic decision-making. Strategic Management Journal, 13(SI). 17-37.

Elkjaer, B. (2003). Social learning theory: Learning as participation in social processes. In M. Smith \& M. Lyles (Eds.) Handbook of organizational learning and knowledge management. London, UK: Blackwell Publishing.

Esses, V., Wagner, U., Wolf, C., Preiser, M., \& Wilbur, C. (2006). Perceptions of national identity and attitudes toward immigrants and immigration in Canada and Germany. International Journal of Intercultural Relations, 30, 653-669.

Ghoshal, S., \& Bartlett, C. (1997). The myth of the generic manager: New resource competencies for management roles. California Management Review, 40(1), 92-107.

Griffith, D. A. (2006). Human capital in the supply chain of global firms. Organizational Dynamics, 35(3), 251-263.

Harvey, M. (1997). "Inpatriation" training: The next challenge for international human resource management. International Journal of Intercultural Relations, 21(3), 393-428.

Harvey \& Buckley. (1997). Managing inpatriate managers: Building a global core competency, Journal of World Business, 32(1), 67-78.

Harvey, M., \& Novicevic, M. (2001). The emergence of the pluralism construct and the inpatriation process. International Journal of Human Resource Management, 12(3), 333-356.

Harvey, M., \& Novicevic, M. (2002). The hypercompetitive global marketplace: The importance of intuition and creativity in expatriate managers. Journal of World Business, 37(2), 19-27.

Harvey, M., \& Novicevic, M. (2006). The world is flat: A perfect storm for global business? Organizational Dynamics, 35(3), 207-219.

Harvey, M., Novicevic, M., \& Kiessling, T. (2001). Hypercompetition and the future of global management in the twenty-first century. Thunderbird Journal of World Business, 43(5), 599-616.

Harvey, M., Novicevic, M., \& Speier, C. (2002). The evolution of strategic human resource systems and their application in a foreign subsidiary context. Asia Pacific Journal of Human Resource Management, 40(3), 167-182.

Harvey, M., Ralston, D., \& Napier, N. (2000). International relocation of inpatriate managers: Assessing and facilitating acceptance in the headquarters organization. International Journal of Intercultural Relations, 24(6), 67-78.

Heimann, B., \& Pittenger, K. (1996). The impact of formal mentorship on socialization and commitment of newcomers. Journal of Managerial Issues, 8, 108-117.

Hullermeier, E. (2005). Experience-based decision-making: A satisfying decision tree approach. IEEE Transactions on Systems, Man, and Cybernetics-Part A: Systems and Humans, 35(5), $641-653$. 
Johnson, W. B. (2002). The intentional mentor: Strategies and guidelines for the practice of mentoring. Professional Psychology: Research and Practice, 33, 88-96.

Keys, D., \& Schwartz, B. (2007). "Leaky" rationality: How research on behavioral decisionmaking challenges normative standards of rationality. Perspectives on Psychological Science, 2(2), $162-180$

Kosic, A., \& Phalet, K. (2006). Ethnic categorization of immigrants: The role of prejudice, perceived acculturation strategies and group size. International Journal of Intercultural Relations, 3 , 769-782.

Kramer, R., \& Tyler, T. (1996). Trust in organizations: Frontiers of theory and research. Thousand Oaks, CA: Sage Publications.

Leonard, N. H., Beauvais, L. L., \& Scholl, R. W. (1999). Work motivation: The incorporation of self-concept-based processes. Human Relations, 52(8), 969-998.

Locke, E. A. (1968). Toward a theory of task motivation and incentives. Organizational Behavior $\mathcal{E}$ Human Performance, 3, 157-189.

Lowell, B., Findlay, A., \& Stewart, E. (2004). Brain strain: Optimising highly skilled migration from developing countries. London, UK: Institute for Public Policy.

Luthans, F., \& Ottemann, R. (1973). Motivation vs. learning approaches to organizational behavior. Business Horizons, 16, 55-62.

Matsuo, H. (2000). Liability of foreignness and the use of expatriates in Japanese multinational corporations in the United States. Sociological Inquiry, 70(1), 88-106.

Mezias, J. (2002). How to identify liabilities of foreignness and assess their effects on multinational corporations. Journal of International Management, 8, 265-282.

Miller, L. (1978). Behavior management. New York: Wiley.

Mischel, W. (2007). Toward a cognitive social learning reconceptialization of personality. In Y. Shoda, D. Cervone, \& G. Downey (Eds.), Persons in context: Building a science of the individual. New York, NY: McGraw-Hill.

Montuori, A., \& Fahim, U. (2004). Cross-cultural encounter as an opportunity for personal growth. Journal of Humanistic Psychology, 44(2), 243-265.

Mruk, C. (2001). Self-esteem research, theory, and practice: Toward a positive psychology of self-esteem (3rd ed.). New York: Springer.

Ocampo, J. (2002). Rethinking the development agenda. Cambridge Journal of Economics, 26, 393-407.

Payne, S. C., \& Huff, A. H. (2005). A longitudinal examination of the influence of mentoring on organizational commitment and turnover. Academy of Management Journal, 48, 176-192.

Porter, L. W., \& Lawler, E. E. (1968). Managerial attitudes and performance. Homewood, IL: Irwin.

Reiche, S. B. (2006). The inpatriate experience in multinational corporations: An exploratory case study in Germany. International Journal of Human Resource Management, 17(9), 1572-1590.

Reiche, S. B. (2007). Knowledge sharing through inpatriate assignments in multinational corporations: A social capital perspective. Unpublished thesis, University of Melbourne, Australia.

Rohmjann, A., Florack, A., \& Piontkowski, U. (2006). The role of discordant acculturation attitudes in perceived threat: An analysis of host and immigrant attitudes in Germany. International Journal of Intercultural Relations, 30, 683-702.

Scullion, H., \& Collings, D. (2006). Global staffing. London, UK: Routledge.

Sethi, D., \& Guisinger, S. (2002). Liability of foreignness to competitive advantage: How multinational enterprises cope with the international business environment. Journal of International Management, 8, 223-240.

Solomon, C. (1995a). Success abroad depends on more than job skills. Personnel Journal, April, $51-60$.

Solomon, C. (1995b). Learning to manage host-country nationals. Personnel Journal, 74(2), $60-67$.

Stiglitz, J. (2003). Globalization, technology, and Asian development. Asian Development Review, 20(2), $1-18$ 
Thompson, G. (2002). The future of globalization. Cooperation and Conflict, 37(3), 247-265.

Vroom, V. H. (1964). Work and motivation. New York, NY: Wiley.

Walsh, S., Shulman, S., \& Maurer, O. (2008). Immigration distress, mental health status and coping among young immigrants: A 1-year follow-up study. International Journal of Intercultural Relations, 32, 371-384.

Ward, C., \& Masgoret, A. M. (2006). An integrative model of attitudes toward immigrants. International Journal of Intercultural Relations, 30, 671-682.

Zadek, S., Hojensgard, N., \& Raynard, P. (2001). Perspectives on the new economy of corporate citizenship. Copenhagen, Denmark: The Copenhagen Centre.

Zhou, M. (1997). Segmented assimilation: Issues, controversies, and recent research on the new second generation. International Migration Review, 31(4), 975-1008.

Michael Harvey is the Distinguished Chair of Global Business at the University of Mississippi and a Professor of Global Management at Bond University, Australia.

Tim Kiessling is an Associate Professor of Business Strategy \& Global Business at Bilkent University, Turkey.

Miriam Moeller is a Lecturer in International Business E Strategy at the University of Queensland, Australia. 